\title{
Clinical Progress Note: Procalcitonin in the Identification of Invasive Bacterial Infections in Febrile Young Infants
}

\author{
Marie E Wang, MD, MPH${ }^{1 *}$, Nivedita Srinivas, MD¹, Russell J McCulloh, MD²
}

\begin{abstract}
${ }^{1}$ Department of Pediatrics, Stanford University School of Medicine and Lucile Packard Children's Hospital Stanford, Stanford, California; ${ }^{2}$ Department of Pediatrics, University of Nebraska College of Medicine and Children's Hospital and Medical Center, Omaha, Nebraska.
\end{abstract}

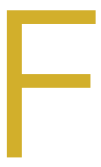

ebrile infants 60 days of age or younger pose a significant diagnostic challenge for clinicians. Most of these infants are well appearing and do not have localizing signs or symptoms of infection, yet they may have serious bacterial infections (SBI) such as urinary tract infection (UTI), bacteremia, and meningitis. While urinalysis is highly sensitive for predicting UTI, ${ }^{1}$ older clinical decision rules and biomarkers such as white blood cell (WBC) count, absolute neutrophil count (ANC), and C-reactive protein (CRP) lack both appropriate sensitivity and specificity for identifying bacteremia and meningitis (ie, invasive bacterial infection $[|B|])_{1}^{2,3}$ which affect approximately $2.4 \%$ and $0.9 \%$ of febrile infants during the first 2 months of life, respectively. ${ }^{4}$ The lack of accurate diagnostic markers can drive overuse of laboratory testing, antibiotics, and hospitalization despite the low rates of these infections. As a result, procalcitonin (PCT) has generated interest because of its potential to serve as a more accurate biomarker for bacterial infections. This review summarizes recent literature on the diagnostic utility of PCT in the identification of IBI in febrile young infants 60 days or younger.

\section{MECHANISM OF PROCALCITONIN}

Procalcitonin is undetectable in noninflammatory states but can be detected in the blood within 4 to 6 hours after initial bacterial infection. ${ }^{5}$ Its production is stimulated throughout various tissues of the body by cytokines such as interleukin-6 and tumor necrosis factor, which are produced in response to bacterial infections. Interferon- $\gamma$, which is produced in response to viral infections, attenuates PCT production. While these characteristics suggest promise for PCT as a more specific screening test for underlying bacterial infection, there are caveats. PCT levels are physiologically elevated in the first 48 hours of life and vary with gestational age, factors that should be considered when interpreting results. ${ }^{6}$ Additionally, PCT levels can rise in other inflammatory states such as autoimmune conditions and certain malignancies, ${ }^{5}$ though these states are unlikely to confound the evaluation of febrile young infants.

*Corresponding Author: Marie Wang, MD, MPH; Email: marie.wang@stanford. edu; Telephone: 650-736-4423; Twitter: @MarieWangMD.

Published online first October 21, 2020

Received: February 25, 2020; Revised: April 13, 2020; Accepted: April 13, 2020

๑ 2021 Society of Hospital Medicine DOI 10.12788/jhm.3451

\section{DIAGNOSTIC ACCURACY OF PROCALCITONIN}

Because of PCT's potential to be more specific than other commonly used biomarkers, multiple studies have evaluated its performance characteristics in febrile young infants. Gomez et al retrospectively evaluated 1,112 well-appearing infants younger than 3 months with fever without a source in seven European emergency departments (EDs). ${ }^{7}$ Overall, 23 infants (2.1\%) had IBI (1 with meningitis). A PCT level of $0.5 \mathrm{ng} / \mathrm{mL}$ or greater was the only independent risk factor for IBI (adjusted odds ratio, $21.69 ; 95 \% \mathrm{Cl}, 7.93-59.28)$. Four infants with IBI had a PCT level less than $0.5 \mathrm{ng} / \mathrm{mL}$, and none of these four had meningitis. PCT was superior to $\mathrm{CRP}, \mathrm{ANC}$, and $\mathrm{WBC}$ in detecting IBI (area under the curve [AUC], 0.825; 95\% Cl, 0.698-0.952). PCT was the also the best marker for identifying $|B|$ among 451 infants with a normal urine dipstick and fever detected $\leq 6$ hours before presentation (AUC, 0.819; 95\% Cl, 0.551-1.087).

In the largest prospective study to date evaluating the diagnostic accuracy of PCT in febrile young infants, Milcent et al studied 2,047 previously healthy infants aged 7-91 days admitted for fever from 15 French EDs. ${ }^{8}$ In total, 21 (1\%) had an $\mathrm{IBI}$ (8 with meningitis). PCT performed better than CRP, ANC, and WBC for the detection of IBI with an AUC of $0.91(95 \% \mathrm{Cl}$, 0.83-0.99). In a multivariable model, a PCT level of $0.3 \mathrm{ng} / \mathrm{mL}$ or greater was the only independent risk factor for IBI with an adjusted odds ratio of $40.3(95 \% \mathrm{Cl}, 5.0-332)$. Only one infant with $\mathrm{IBI}$ had a PCT level less than $0.3 \mathrm{ng} / \mathrm{mL}$. This infant was 83 days old, had 4 hours of fever, and became afebrile spontaneously prior to the blood culture revealing Streptococcus pneumoniae. PCT also performed better than CRP in the detection of IBI in infants 7-30 days of age and those with fever for less than 6 hours, though both subgroups had small numbers of infants with IBI. The authors determined that a PCT level of $0.3 \mathrm{ng} / \mathrm{mL}$ was the optimal cutoff for ruling out $\mid \mathrm{Bl}$; this cutoff had a sensitivity of $90 \%$ and negative likelihood ratio (LR) of 0.1 (Table). In contrast, the more commonly studied PCT cutoff of $0.5 \mathrm{ng} / \mathrm{mL}$ increased the negative LR to 0.2. The authors suggested that PCT, when used in the context of history, exam, and tests such as urinalysis, could identify infants at low risk of IBI.

Gomez et al conducted a prospective, single-center study of well-appearing infants with fever without a source and negative urine dipsticks. ${ }^{9}$ They identified IBI in 9 of 196 infants (4.5\%) 21 days or younger and 13 of 1,331 infants (1.0\%) 22-90 days old. PCT was superior to CRP and ANC for IBI detection in both age groups. However, in infants 21 days or younger, both the positive and negative LRs for PCT levels of $0.5 \mathrm{ng} / \mathrm{mL}$ 
TABLE. Performance of Procalcitonin (PCT) and Clinical Decision Rules in the Detection of Invasive Bacterial Infection in Febrile Young Infants

\begin{tabular}{|c|c|c|c|c|}
\hline & $\begin{array}{l}\text { Sensitivity } \\
(95 \% \mathrm{Cl})\end{array}$ & $\begin{array}{l}\text { Specificity } \\
(95 \% \mathrm{Cl})\end{array}$ & $\begin{array}{l}\text { Positive LR } \\
(95 \% \mathrm{Cl})\end{array}$ & $\begin{array}{l}\text { Negative LR } \\
(95 \% \mathrm{Cl})\end{array}$ \\
\hline \multicolumn{5}{|c|}{ Procalcitonin alone (PCT cutoff [ng/mL]) } \\
\hline Milcent ${ }^{8}(\geq 0.3)$ & $90(68-99)$ & $78(75-80)$ & $4.0(3.3-4.8)$ & $0.1(0.03-0.4)$ \\
\hline Gomez ${ }^{9}$ - Infants $22-90$ days old $(\geq 0.5)$ & $54(29-77)$ & $95(93-96)$ & $9.72(5.61-16.86)$ & $0.49(0.27-0.88)$ \\
\hline \multicolumn{5}{|l|}{ Select risk stratification rules with PCT } \\
\hline Step-by-Step ${ }^{10, a}$ & $92(84-96)$ & $47(45-49)$ & $1.73(1.61-1.85)$ & $0.17(0.08-0.4)$ \\
\hline \multicolumn{5}{|c|}{ Select risk stratification rules without PCT } \\
\hline Rochester criteria - Aronson ${ }^{12, c}$ & $82(74-88)$ & $60(54-66)$ & $2.0(1.7-2.4)$ & $0.3(0.2-0.4)$ \\
\hline Modified Philadelphia criteria ${ }^{12, \mathrm{~d}}$ & $92(86-96)$ & $35(29-41)$ & $1.4(1.3-1.6)$ & $0.2(0.1-0.4)$ \\
\hline \multicolumn{5}{|c|}{$\begin{array}{l}\text { aThe Step-by-Step approach uses a PCT cutoff of } \geq 0.5 \mathrm{ng} / \mathrm{mL} \text {, in addition to the following characteristics to identify patients who are not low risk: ill appearance, age } \leq 21 \text { days, positive urine } \\
\text { dipstick, CRP }>20 \mathrm{mg} / \mathrm{L} \text {, and ANC }>10,000 / \mu \mathrm{L} \text {. }\end{array}$} \\
\hline \multicolumn{5}{|c|}{$\begin{array}{l}\text { 'These data from Kupperman et al represent performance of the PECARN rule with the outcome of } \mathrm{IBI} \text { when using a positive urinalysis and nonrounded cutoffs (PCT }>1.71 \mathrm{ng} / \mathrm{mL} \text { and ANC } \\
>4,090 / \mathrm{\mu L} \text { ) to identify patients who are not low risk. }\end{array}$} \\
\hline \multicolumn{5}{|c|}{$\begin{array}{l}\text { cRochester low-risk criteria: Previously healthy, no skin or soft tissue infection, normal urinalysis, peripheral WBC of } \geq 5,000 \text { and } \leq 15,000 / \mathrm{mm} 3 \text {, and absolute band count of } \leq 1,500 \text { per } \mu L \text {. Infants } \\
\text { who do not fulfill all of these criteria are considered to not be low risk. }\end{array}$} \\
\hline \multicolumn{5}{|c|}{$\begin{array}{l}\text { ¿Modified Philadelphia low-risk criteria: Age }>28 \text { days, previously healthy, no skin or soft tissue infection, normal urinalysis, peripheral WBC of } \geq 5,000 \text { and } \leq 15,000 / \mathrm{mm} 3 \text {, and bands-to-total } \\
\text { neutrophil ratio of }<0.2 \text {. Infants who do not fulfill all of these criteria are considered to not be low risk. }\end{array}$} \\
\hline \multicolumn{5}{|c|}{ Abbreviations: IBI, invasive bacterial infection; LR, likelihood ratio; N/A, not applicable; NR, not reported; PECARN, Pediatric Emergency Care Applied Research Network; PCT, procalcitonin. } \\
\hline
\end{tabular}

or greater were poor (Table). Differences in results from the prior two studies 7,8 may be related to smaller sample size and differences in patient population because this study included infants younger than 7 days and a higher proportion of infants presenting within 6 hours of fever.

\section{CLINICAL DECISION RULES}

PCT has also been incorporated into clinical decision rules for febrile young infants, primarily to identify those at low risk of either $\mid \mathrm{BI}$ or SBI. The Step-by-Step approach ${ }^{10}$ classified well-appearing febrile infants 90 days or younger as having a high risk of IBI if they were ill appearing, younger than 21 days old, had a positive urine dipstick or a PCT level of $0.5 \mathrm{ng} / \mathrm{mL}$ or greater, and classified them as intermediate risk if they had a CRP level greater than $20 \mathrm{mg} / \mathrm{L}$ or ANC level greater than $10,000 / \mathrm{LL}$. The remaining infants were classified as low risk and could be managed as outpatients without lumbar puncture or empiric antibiotics. Of note, derivation of this rule excluded patients with respiratory signs or symptoms. In a prospective validation study with 2,185 infants from 11 European EDs, 87 (4.0\%) had an IBI (10 with bacterial meningitis). Sequentially identifying patients as high risk using general appearance, age, and urine dipstick alone identified $80 \%$ of infants with $\mathrm{IBI}$ and $90 \%$ of those with bacterial meningitis. The remaining case of meningitis would have been detected by an elevated PCT. A total of 7 of 991 infants (0.7\%) classified as low risk had an IBI and none had meningitis. Six of these infants had a fever duration of less than 2 hours, which would not be enough time for PCT to rise. The Step-by-Step approach, with a sensitivity of 92\% and negative LR of 0.17 , performed well in the ability to rule out IBI.

A clinical prediction rule developed by the Pediatric Emergency Care Applied Research Network (PECARN) found that urinalysis, ANC, and PCT performed well in identifying infants 60 days or younger at low risk for SBI and IBI. ${ }^{11}$ This prospective observational study of 1,821 infants 60 days or younger in 26 US EDs found 170 (9.3\%) with SBI and 30 (1.6\%) with IBI; 10 had bacterial meningitis. Only one patient with IBI was classified as low risk, a 30-day-old whose blood culture grew Enterobacter cloacae and who had a negative repeat blood culture prior to antibiotic treatment. Together, a negative urinalysis, ANC of $4,090 / \mu \mathrm{L}$ or less, and PCT level of $1.71 \mathrm{ng} / \mathrm{mL}$ or less were excellent in predicting infants at low risk for both $\mathrm{SBI}$ and $\mathrm{IBI}$, with a sensitivity of $97 \%$ and negative LR of 0.05 for the outcome of IBI. When applying these variables with "rounded cutoffs" of PCT levels less than $0.5 \mathrm{ng} / \mathrm{mL}$ (chosen by the authors because it is a more commonly used cutoff) and ANC of $4,000 / \mu \mathrm{L}$ or less to identify infants at low risk for $\mathrm{SBI}$, their performance was similar to nonrounded cutoffs. Data for the rule with rounded 
cutoffs in identifying infants at low risk for IBI were not presented. The PECARN study was limited by the small numbers of infants with IBIs, and the authors recommended caution when applying the rule to infants 28 days or younger.

Older clinical decision rules without PCT, such as the Rochester and modified Philadelphia criteria, use clinical and laboratory features to assess risk of IBI. ${ }^{3}$ Recent studies have evaluated these criteria in cohorts with larger numbers of infants with $|\mathrm{B}|$ since the derivation studies included mostly infants with $\mathrm{SBI}$ and small numbers with IBI. ${ }^{3}$ Gomez et al demonstrated that the Rochester criteria had lower sensitivity and higher negative LR than the Step-by-Step approach in IBI detection. ${ }^{10}$ In a case-control study of 135 cases of IBI with 249 matched controls, Aronson et al reported that the modified Philadelphia criteria had higher sensitivity but lower specificity than the Rochester criteria for IBI detection. ${ }^{12}$ The ability of the Rochester and modified Philadelphia criteria to rule out IBI, as demonstrated by the negative LR (range 0.2-0.4), was inferior to the negative LRs documented by Milcent et $\mathrm{l}^{8}$ (PCT cutoff value of $0.3 \mathrm{ng} / \mathrm{mL}$ ), the Step-by-Step approach, ${ }^{10}$ and the PECARN rule $^{11}$ (range 0.05-0.17; Table). However, clinical decision rules with and without PCT suffer similar limitations in having poor specificity in identifying infants likely to have IBI.

\section{GAPS IN THE LITERATURE}

Several key knowledge gaps around PCT use for diagnosing neonatal infections exist. First, the optimal use of PCT in context with other biomarkers and clinical decision rules remains uncertain. A meta-analysis of 28 studies involving over 2,600 infants that compared PCT level (with and without CRP) with isolated CRP and presepsin levels found that PCT in combination with CRP had greater diagnostic accuracy than either PCT or CRP alone, which highlights a potential opportunity for prospective study. ${ }^{13}$ Second, more data are needed on the use of PCT in the $\leq 28$-day age group given the increased risk of both $\mid \mathrm{BI}$ and neonatal herpes simplex virus infection (HSV), compared with that in the second month of life. Neonatal HSV poses diagnostic challenges because half of infants will initially present as afebrile, ${ }^{14}$ and delays in initiating antiviral treatment dramatically increase the risk of permanent disability or death. ${ }^{15}$ There have been no prospective studies evaluating PCT use as part of neonatal HSV evaluations.

\section{CLINICAL APPLICATIONS AND CONCLUSIONS}

In summary, PCT can play an important adjunctive diagnostic role in the evaluation of febrile young infants, especially during the second month of life when outpatient management is more likely to be considered. PCT is superior to other inflammatory markers in identifying $\mid \mathrm{BI}$, though the optimal cutoffs to maximize sensitivity and specificity are uncertain. Its performance characteristics, both alone and within clinical decision rules, can help clinicians better identify children at low risk for $\mid \mathrm{BI}$ when compared with clinical decision rules without PCT. PCT measurement can help clinicians miss fewer infants with $\mid \mathrm{BI}$ and identify infants for whom safely doing less is an appropriate option, which can ultimately reduce costs and hos- pitalizations. PCT may be particularly helpful when the clinical history is difficult to assess or when other diagnostic test results are missing or give conflicting results. Centers that use PCT will need to ensure that results are available within a short turnaround time (a few hours) in order to meaningfully affect care. Future studies of PCT in febrile infant evaluations should focus on identifying optimal strategies for incorporating this biomarker into risk assessments that present information to parents in a way that enables them to understand their child's risk of a serious infection.

Disclosures: Dr McCulloh receives support from the Office of the Director of the National Institutes of Health under award UG1OD024953. Dr McCulloh from time to time provides advice on legal matters. Drs Wang and Srinivas have nothing to disclose.

\section{References}

1. Tzimenatos L, Mahajan P, Dayan PS, et al. Accuracy of the urinalysis for urinary tract infections in febrile infants 60 days and younger. Pediatrics. 2018;141(2):e20173068. https://doi.org/10.1542/peds.2017-3068

2. Cruz AT, Mahajan P, Bonsu BK, et al. Accuracy of complete blood cell counts to identify febrile infants 60 days or younger with invasive bacterial infections. JAMA Pediatr. 2017;171(11):e172927. https://doi.org/10.1001/ jamapediatrics.2017.2927

3. Hui C, Neto G, Tsertsvadze A, et al. Diagnosis and management of febrile infants (0-3 months). Evid Rep Technol Assess (Full Rep). 2012;(205):1-297.

4. Biondi EA, Lee $B$, Ralston $S L$, et al. Prevalence of bacteremia and bacterial meningitis in febrile neonates and infants in the second month of life: a systematic review and meta-analysis. JAMA Netw Open. 2019;2(3):e190874. https://doi.org/10.1001/jamanetworkopen.2019.0874

5. Fontela PS, Lacroix J. Procalcitonin: is this the promised biomarker for critically ill patients? J Pediatr Intensive Care. 2016;5(4):162-171. https://doi. org/10.1055/s-0036-1583279

6. Chiesa $\mathrm{C}$, Natale F, Pascone $\mathrm{R}$, et al. $\mathrm{C}$ reactive protein and procalcitonin: reference intervals for preterm and term newborns during the early neonatal period. Clin Chim Acta. 2011;412(11-12):1053-1059. https://doi.org/10.1016/j. cca.2011.02.020

7. Gomez B, Bressan S, Mintegi S, et al. Diagnostic value of procalcitonin in well-appearing young febrile infants. Pediatrics. 2012;130(5):815-822. https:// doi.org/10.1542/peds.2011-3575

8. Milcent K, Faesch S, Gras-Le Guen C, et al. Use of procalcitonin assays to predict serious bacterial infection in young febrile infants. JAMA Pediatr. 2016;170(1):62-69. https://doi.org/10.1001/jamapediatrics.2015.3210

9. Gomez B, Diaz H, Carro A, Benito J, Mintegi S. Performance of blood biomarkers to rule out invasive bacterial infection in febrile infants under 21 days old. Arch Dis Child. 2019;104(6):547-551. https://doi.org/10.1136/ archdischild-2018-315397

10. Gomez B, Mintegi S, Bressan S, et al. Validation of the "step-by-step" approach in the management of young febrile infants. Pediatrics. 2016;138(2):e20154381. https://doi.org/10.1542/peds.2015-4381

11. Kuppermann N, Dayan PS, Levine DA, et al. A clinical prediction rule to identify febrile infants 60 days and younger at low risk for serious bacterial infections. JAMA Pediatr. 2019;173(4):342-351. https://doi.org/10.1001/jamapediatrics.2018.5501

12. Aronson PL, Wang ME, Shapiro ED, et al. Risk stratification of febrile infants $\leq 60$ days old without routine lumbar puncture. Pediatrics. 2018;142(6):e20181879. https://doi.org/10.1542/peds.2018-1879

13. Ruan L, Chen GY, Liu Z, et al. The combination of procalcitonin and C-reactive protein or presepsin alone improves the accuracy of diagnosis of neonatal sepsis: a meta-analysis and systematic review. Crit Care. 2018;22(1):316. https://doi.org/10.1186/s13054-018-2236-1

14. Brower L, Schondelmeyer A, Wilson P, Shah SS. Testing and empiric treatment for neonatal herpes simplex virus: challenges and opportunities for improving the value of care. Hosp Pediatr. 2016;6(2):108-111. https://doi. org/10.1542/hpeds.2015-0166

15. Long SS. Delayed acyclovir therapy in neonates with herpes simplex virus infection is associated with an increased odds of death compared with early therapy. Evid Based Med. 2013;18(2):e20. https://doi.org/10.1136/eb-2012100674 